Article

\title{
Camellia sinensis L. Extract and Its Potential Beneficial Effects in Antioxidant, Anti-Inflammatory, Anti-Hepatotoxic, and Anti-Tyrosinase Activities
}

\author{
Surached Thitimuta ${ }^{1}$, Pimolpan Pithayanukul ${ }^{1, *}$, Saruth Nithitanakool ${ }^{1}$, Rapepol Bavovada ${ }^{2}$, \\ Jiraporn Leanpolchareanchai ${ }^{1}$ and Patchreenart Saparpakorn ${ }^{3}$ \\ 1 Department of Pharmacy, Faculty of Pharmacy, Mahidol University, Bangkok 10400, Thailand; \\ surached15@yahoo.com (S.T.); saruth_pipe@yahoo.com (S.N.); jiraporn.lea@mahidol.ac.th (J.L.) \\ 2 Department of Pharmacognosy and Pharmaceutical Botany, Faculty of Pharmaceutical Sciences, \\ Chulalongkorn University, Bangkok 10330, Thailand; rapepol1@hotmail.com \\ 3 Department of Chemistry, Faculty of Science, Kasetsart University, Bangkok 10900, Thailand; \\ fscipnsk@ku.ac.th \\ * Correspondence: pimolpan.pit@mahidol.ac.th; Tel.: +66-2-644-8694
}

Academic Editor: Declan P. Naughton

Received: 17 January 2017; Accepted: 2 March 2017; Published: 4 March 2017

\begin{abstract}
The aims of this study were to investigate the potential benefits of antioxidant, anti-inflammatory, anti-hepatotoxic, and anti-tyrosinase activities of a methanolic extract of fresh tea leaves (FTE) (Camellia sinensis L.). The antioxidant capacity was investigated using three different methods at different temperatures. The anti-inflammatory activity was studied in vitro by the inhibition of 5-lipoxygenase assay. The anti-hepatotoxic effect was investigated in $\mathrm{CCl}_{4}$-induced liver injury in rats. The anti-tyrosinase activities of the FTE and its principal phenolic compounds were investigated in L-3,4-dihydroxyphenylalanine (L-DOPA) oxidation by a mushroom tyrosinase. A molecular docking study was conducted to determine how the FTE's principal catechins interact with the tyrosinase. The FTE exhibited the best shelf life at low temperatures and demonstrated concentration-dependent antioxidant, anti-inflammatory, anti-hepatotoxic, and anti-tyrosinase effects compared to positive references. Treatment of rats with the FTE at $2000 \mathrm{mg} / \mathrm{kg} /$ day for 28 consecutive days reversed $\mathrm{CCl}_{4}$-induced oxidative damage in hepatic tissues by lowering the levels of alanine aminotransferase by $69 \%$ and malondialdehyde by $90 \%$. Our findings suggest that the FTE has the capacity to scavenge free radicals and can protect against oxidative stress induced by $\mathrm{CCl}_{4}$ intoxication. The docking results were consistent with our in vitro data, indicating the anti-tyrosinase potency of the principal catechins.
\end{abstract}

Keywords: Camellia sinensis L.; antioxidant; anti-inflammatory; anti-hepatotoxic; anti-tyrosinase; molecular modelling

\section{Introduction}

Free radicals and reactive oxygen species (ROS), from both endogenous and exogenous sources, have been implicated in the aetiology of several degenerative diseases, including inflammation and some hepatopathies [1]. Numerous manifestations of liver damage have been proven to be associated with redox imbalance and oxidative stress [2]. Compounds that exhibit antioxidant properties, scavenging of free radicals, and inhibition of lipid peroxidation are reported to show hepatoprotective activity [3]. Natural antioxidants exhibit a wide range of pharmacological activities and have been shown to possess multifunctional pharmacological activities such as anti-inflammatory and anti-aging properties. There has been a great deal of interest in edible plants that contain antioxidants and 
health-promoting phytochemicals in view of their health implications. It has become evident that phenolic compounds from natural products can reduce oxidative stress by indirect antioxidant action. Various flavonoids, which are found naturally in fruits, vegetables, and some beverages, have been demonstrated to exert antioxidant effects through a number of different mechanisms. Tea (Camellia sinensis L.; family Theaceae), the most popular and widely cultivated beverage in Southeast Asia, has received considerable attention among scientists due to its beneficial health effects. The health benefits associated with tea consumption have been attributed in part to the antioxidant activity and free radical-scavenging ability of the most abundant tea catechins [4-6]. The principal catechins present in tea leaves are epigallocatechin gallate (EGCG), epigallocatechin (EGC), epicatechin gallate (ECG), gallocatechin (GC), epicatechin (EC), and catechin. The amount of these compounds, which depends on tea variety, has been regarded as a quality indicator of tea [7]. Various biological functions of green tea, including antioxidant activities [8-10], anti-inflammatory activities [11], anti-melanogenic effects [12], and hepatoprotection [13-17], have been reported.

Tyrosinase (E.C. 1.14.18.1), a multifunctional Cu-containing enzyme that is widely distributed in nature, is found in vegetables, fruits, and mushrooms and has a key role in the browning that occurs upon brushing or long-term storage [18]. In mammals, it is a rate-limiting enzyme for melanogenesis and is responsible for skin pigmentation abnormalities such as flecks and defects [19,20]. Melanogenesis is involved in the first two steps of melanin biosynthesis, which consists of the hydroxylation of L-tyrosine and the oxidation of the product of this reaction, L-3,4-dihydroxyphenylalanine (L-DOPA), to the corresponding $o$-quinone [21]. Tyrosinase has also been linked to neurodegenerative diseases through its role in oxidizing excess dopamine to produce DOPA quinones, which are highly reactive compounds that induce neuronal damage and cell death. Most melanin synthesis inhibitors inhibit melanogenesis by inhibiting tyrosinase activity [22-24]. The crystallographic structure of tyrosinase has been recently established [25], enabling a closer look at its three-dimensional structure and a better understanding of its mechanism of action [26].

The aims of this study were to evaluate the potential benefits of a methanolic extract from fresh tea leaves (FTE) of Camellia sinensis L. cultivar Oolong No. 12 in terms of anti-lipid peroxidation, free-radical scavenging, metal chelation, and anti-inflammation in vitro. The effects of different temperatures and storage durations on the anti-lipid peroxidation activity of the FTE were also investigated. Anti-hepatotoxic activity was determined against carbon tetrachloride $\left(\mathrm{CCl}_{4}\right)$-induced liver damage in rats. Moreover, the inhibitory effect of this plant extract on L-DOPA oxidation by mushroom tyrosinase was investigated. A molecular docking method using the Gold v3.2 program [27] was performed to elucidate the activity of the extract. Understanding how the principal catechins in the extract interact with tyrosinase may explain how tea catechins inhibit tyrosinase and melanin formation.

\section{Results and Discussion}

\subsection{Antioxidant Activity Assay}

\subsubsection{Determination of Lipid Peroxidation Inhibition Using the Ferric Thiocyanate (FTC) Method}

At a concentration of $100 \mu \mathrm{g} / \mathrm{mL}$, the FTE delayed the oxidation of linoleic acid compared to the reference standards (butylated hydroxyanisole; BHA, butylated hydroxytoluene; BHT and tocopherol) and, based on the low absorbance values observed, exhibited significantly higher activity than ascorbic acid (AsA) and the control $(p<0.05)$ at $30^{\circ} \mathrm{C}$ (Figure 1A). The extract demonstrated potent inhibition of lipid peroxidation of up to $85 \%-95 \%$ during the storage period of 120 days at $8{ }^{\circ} \mathrm{C}$ and 60 days at $30{ }^{\circ} \mathrm{C}$, but less than $5 \%$ inhibition at $40{ }^{\circ} \mathrm{C}$ (Figure $1 \mathrm{~B}, \mathrm{C}$ ). These results reflect the instability of the FTE at high temperatures. This finding was not surprising because heating causes acceleration of the initial reactions that result in a decrease of the activity of the added antioxidants [28]. 
A

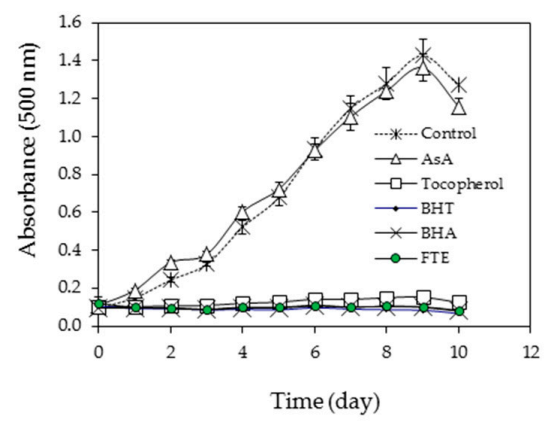

B

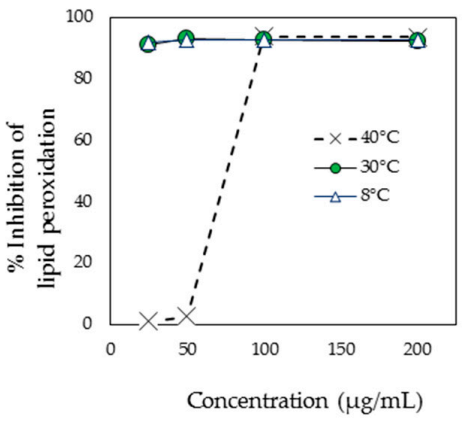

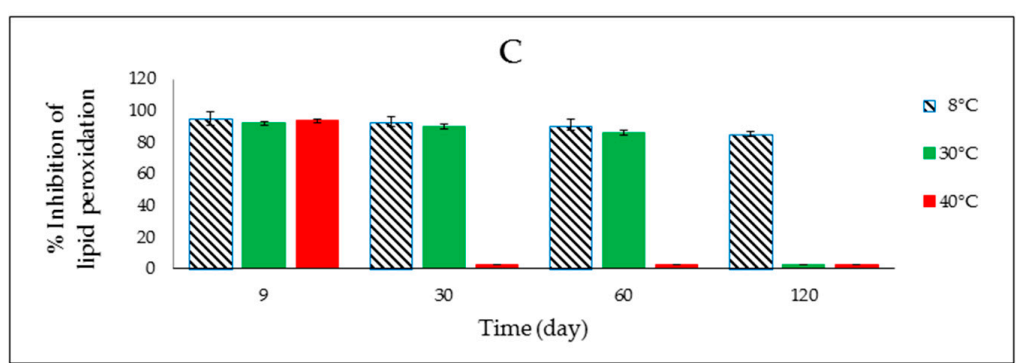

Figure 1. The effect of a methanolic extract of fresh tea leaves (FTE) and the positive references on the lipid peroxidation of a linoleic acid emulsion as measured by the formation of ferric thiocyanate. (A) Time course of linoleic acid peroxidation at $30{ }^{\circ} \mathrm{C}$ in the absence or presence of samples at a concentration of $100 \mu \mathrm{g} / \mathrm{mL}(n=2)$; (B) Percent inhibition of lipid peroxidation as a function of sample concentration on day 9 of peroxidation at various temperatures $(n=2)$; (C) Percent inhibition of lipid peroxidation by the FTE $(200 \mu \mathrm{g} / \mathrm{mL})$ versus time (day) at various temperatures $(n=2)$.

2.1.2. Determination of Free Radical Scavenging Activity Using the 2,2-Diphenyl-1-picrylhydrazyl (DPPH) Assay

The reduction of DPPH by the FTE occurred in a concentration-dependent manner (Figure 2). The percent inhibition of DPPH was more pronounced in the presence of the FTE compared to AsA, BHA, BHT, and tocopherol, suggesting highly efficient free radical-scavenging activity. The order of potency, as determined by the $50 \%$ inhibition of the DPPH scavenging effect $\left(\mathrm{SC}_{50}\right)$, was FTE $>$ BHA $>$ tocopherol $>$ AsA $>$ BHT (Table 1). The powerful antioxidant activity of the FTE was primarily attributed to the presence of tea catechins [29].

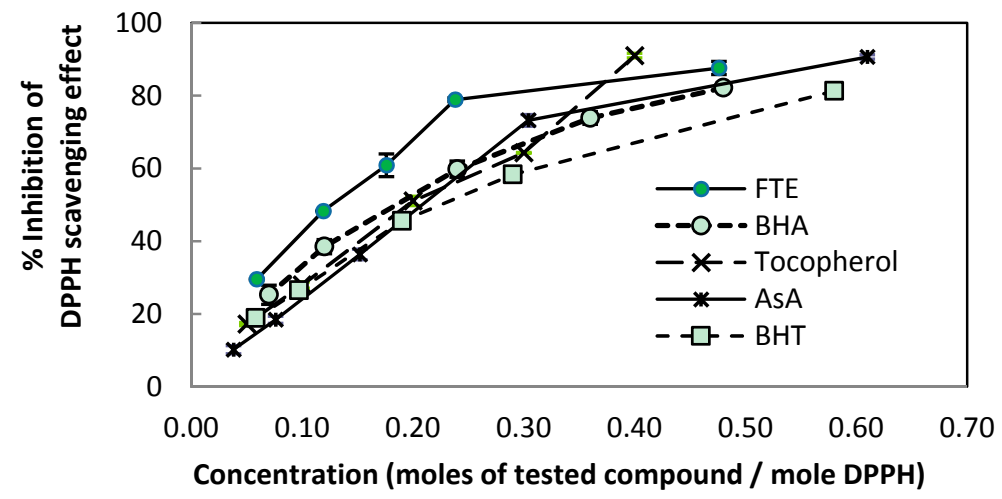

Figure 2. The percent inhibition of DPPH radical-scavenging activity. Data are expressed as the mean \pm standard deviation (SD) $(n=2)$. The values are significantly different at $p<0.05$. The reduction of the DPPH radical was measured by the decrease of absorbance at $515 \mathrm{~nm}$ as a function of the concentration of the FTE and the reference standards. 
Table 1. The $50 \%$ inhibition of the DPPH scavenging effect, $\mathrm{SC}_{50}$ (moles of tested compound/mole $\mathrm{DPPH})$, induced by the FTE and the reference standards.

\begin{tabular}{cc}
\hline Tested Samples & SC $_{\mathbf{5 0}}$ (Moles of Tested Compound/Mole DPPH) \\
\hline FTE & $0.128 \pm 0.004$ \\
Reference standards: & $0.184 \pm 0.011$ \\
BHA & $0.224 \pm 0.005$ \\
BHT & $0.196 \pm 0.005$ \\
Tocopherol & $0.209 \pm 0.006$ \\
AsA &
\end{tabular}

\subsubsection{Chelation of Ferrous Metal Ions}

The FTE exhibited a metal-chelating effect in a concentration-dependent manner (Figure 3). Based on the $\mathrm{IC}_{50}$ in Table 2, the iron chelation capacity of the FTE $(2.08 \pm 0.10 \mathrm{mg} / \mathrm{mL})$ was much lower than that of ethylenediaminetetraacetic acid (EDTA) $(0.01 \pm 0.00 \mathrm{mg} / \mathrm{mL})$, which reflected the natural iron chelation capacity of the FTE and the ability of the FTE to bind iron. These factors might also contribute to its inhibition of lipid peroxidation.

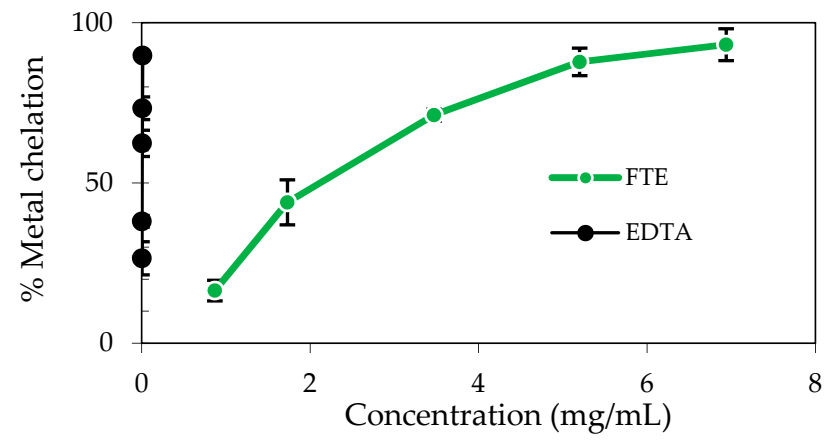

Figure 3. The metal chelating effect of the FTE and EDTA. Data are expressed as the mean $\pm \operatorname{SD}(n=2)$.

Table 2. The constituents and contents of the FTE and the concentration providing $50 \%$ inhibition of the iron(II) chelating capacity, lipoxygenase, and tyrosinase activities of the FTE and its four isolated pure compounds, including reference standards. The values represent the mean $\pm \mathrm{SD}$ or the mean \pm standard error of the mean (SEM).

\begin{tabular}{|c|c|c|c|c|c|}
\hline \multirow[b]{2}{*}{ FTE and Its Isolated Compounds } & \multicolumn{2}{|c|}{ Contents $^{\mathrm{a}}$} & \multirow[b]{2}{*}{$\begin{array}{l}\text { Iron(II)-Chelating } \\
{ }^{\mathrm{b}}\left(\mathrm{IC}_{50}, \mathrm{mg} / \mathrm{mL}\right)\end{array}$} & \multirow[b]{2}{*}{$\begin{array}{l}\text { Anti-Lipoxygenase } \\
{ }^{b}\left(\mathrm{IC}_{50}, \mu \mathrm{g} / \mathrm{mL}\right)\end{array}$} & \multirow[b]{2}{*}{$\begin{array}{l}\text { Anti-Tyrosinase }{ }^{a} \\
\quad\left(\mathrm{IC}_{50}, \mu \mathrm{g} / \mathrm{mL}\right)\end{array}$} \\
\hline & $\begin{array}{c}\% \\
w / w\end{array}$ & $\begin{array}{c}\text { mg/g Dry } \\
\text { Weight }\end{array}$ & & & \\
\hline FTE $^{c}$, total phenolic content & 24.52 & $245.20 \pm 4.92$ & $2.08 \pm 0.10$ & $30.60 \pm 0.40$ & $349.00^{\mathrm{d}} \pm 9.00$ \\
\hline \multicolumn{6}{|l|}{ Constituents: } \\
\hline Epicatechin (EC) & 1.60 & $16.05 \pm 0.25$ & - & - & $\mathrm{Nd}$ \\
\hline Epicatechin-3-gallate (ECG) & 1.17 & $11.70 \pm 0.20$ & - & - & $76.50^{\mathrm{d}, \mathrm{e}} \pm 1.50$ \\
\hline Epigallocatechin (EGC) & 8.97 & $89.70 \pm 2.00$ & - & - & $110.00^{\mathrm{d}, \mathrm{e}} \pm 0.00$ \\
\hline Epigallocatechin-3-gallate (EGCG) & 7.21 & $72.10 \pm 2.30$ & - & - & $234.00^{\mathrm{d}, \mathrm{e}} \pm 6.00$ \\
\hline Unidentified phenolic content & 5.57 & - & - & - & - \\
\hline \multicolumn{6}{|l|}{ Reference Standards: } \\
\hline Ethylenediaminetetraacetic acid (EDTA) & & - & $0.01 \pm 0.00$ & - & - \\
\hline Nordihydroguaiaretic acid (NDGA) & & - & - & $59.26 \pm 0.92$ & - \\
\hline Kojic acid (KA) & & - & - & - & $2.28 \pm 0.03$ \\
\hline
\end{tabular}

${ }^{a}$ The values are mean \pm SEM. ${ }^{b}$ The values are mean \pm SD. ${ }^{c}$ FTE concentration was calculated based on the gallic acid equivalent (GAE, $\mathrm{mg} / \mathrm{g}$ of extract). ${ }^{\mathrm{d}}$ Significant difference compared to kojic acid $(p<0.05)$; ${ }^{\text {e }}$ Significant difference compared to FTE $(p<0.05)$; Nd = Not detectable.

\subsection{Determination of In Vitro Anti-Inflammatory Activity by the Inhibition of 5-Lipoxygenase (5-LOX)}

The extract exhibited a concentration-dependent inhibition of soybean lipoxygenase with an $\mathrm{IC}_{50}$ of $30.60 \pm 0.40 \mu \mathrm{g} / \mathrm{mL}$ compared to that of the reference standard (nordihydroguaiaretic acid, NDGA), 
with an $\mathrm{IC}_{50}$ of $59.26 \pm 0.92 \mu \mathrm{g} / \mathrm{mL}$ (Figure 4, Table 2). Inflammatory processes become pathogenic due to lipoxygenase catalysing the synthesis of leukotrienes via the transfer of oxygen radicals [30]. It is possible that the termination of leukotriene biosynthesis by the FTE could be attributed to the potential abilities of the FTE to scavenge free radicals generated within the active site of the enzyme. The results of this study support earlier reports that natural products possess the ability to inhibit 5-LOX in addition to free radical-scavenging activity [31].

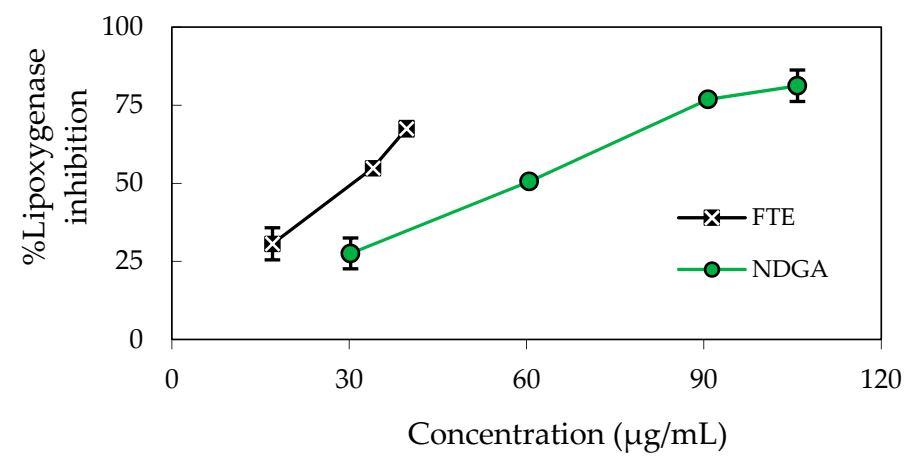

Figure 4. The percent inhibition of soybean lipoxygenase among varying concentrations of the FTE and the positive reference (NDGA). Data are expressed as the mean $\pm \mathrm{SD}(n=3)$.

\subsection{Determination of the Anti-Hepatotoxic Effects of the FTE on $\mathrm{CCl}_{4}$-Induced Liver Injury in Rats}

The activities of the biochemical parameters in the normal control, $\mathrm{CCl}_{4}$, the positive control, and the treated groups of rats with $\mathrm{CCl}_{4}$-induced liver injury are presented in Table 3 . The activities of alanine aminotransferase (ALT) and malondialdehyde (MDA) were significantly $(p<0.05)$ increased in the groups treated with $\mathrm{CCl}_{4}$ compared to the normal controls. Daily treatment with the FTE at a dose of $500 \mathrm{mg} / \mathrm{kg}$ produced a marginal change in ALT (3.16\%) and MDA (24.44\%) activities, while higher doses $(1000 \mathrm{mg} / \mathrm{kg}$ and $2000 \mathrm{mg} / \mathrm{kg})$ of the FTE produced a dose-dependent, significant decrease in serum ALT (69\%) and hepatic MDA (90\%) when compared with the levels in the $\mathrm{CCl}_{4}$ control $(p<0.05)$. The reversing effect of the group treated with silymarin towards normalization was more potent at $80 \%$ for ALT and 79\% for MDA. There were no significant changes in ALT and MDA activities in healthy rats treated with the extract alone. The abnormally high serum levels of ALT (301.04 $\pm 13.88 \mathrm{U} / \mathrm{L})$ and MDA $\left(0.14 \pm 0.01 \mathrm{nmol} / \mathrm{g}\right.$ liver) observed in the $\mathrm{CCl}_{4}$-treated rats reflected the consequences of $\mathrm{CCl}_{4}$-induced liver dysfunction and indicated oxidative damage to hepatic cells compared to the normal treated group $(\mathrm{ALT}=25.49 \pm 2.41 \mathrm{U} / \mathrm{L}, \mathrm{MDA}=0.02 \pm 0.00 \mathrm{nmol} / \mathrm{g}$ liver $)$

Table 3. The effect of the FTE on serum ALT and hepatic MDA in liver injury induced by $\mathrm{CCl}_{4}$ in rats.

\begin{tabular}{lll}
\hline \multicolumn{1}{c}{ Groups } & \multicolumn{1}{c}{ ALT (U/L) } & \multicolumn{1}{c}{ MDA (nmol/g Liver) } \\
\hline Normal & $25.49 \pm 2.41$ & $0.02 \pm 0.00$ \\
CCl $_{4}$ & $301.04^{\mathrm{a}} \pm 13.88$ & $0.14^{\mathrm{a}} \pm 0.01$ \\
FTE $(500 \mathrm{mg} / \mathrm{kg})+\mathrm{CCl}_{4}$ & $292.34 \pm 9.38(3.16 \%)^{\mathrm{b}}$ & $0.12 \pm 0.01(24.44 \%){ }^{\mathrm{b}}$ \\
FTE $(1000 \mathrm{mg} / \mathrm{kg})+\mathrm{CCl}_{4}$ & $206.42^{\mathrm{c}} \pm 18.42(34.34 \%)^{\mathrm{b}}$ & $0.09^{\mathrm{c}} \pm 0.02(48.96 \%)$ \\
FTE $(2000 \mathrm{mg} / \mathrm{kg})+\mathrm{CCl}_{4}$ & $111.64^{\mathrm{c}} \pm 2.91(68.74 \%)^{\mathrm{b}}$ & $0.04^{\mathrm{c}} \pm 0.00(90.27 \%)^{\mathrm{b}}$ \\
FTE $(2000 \mathrm{mg} / \mathrm{kg})$ & $28.64^{\mathrm{c}} \pm 2.39$ & $0.03^{\mathrm{c}} \pm 0.00$ \\
Silymarin $(100 \mathrm{mg} / \mathrm{kg})+\mathrm{CCl}_{4}$ & $79.38^{\mathrm{c}} \pm 28.22(80.43 \%)^{\mathrm{b}}$ & $0.05^{\mathrm{c}} \pm 0.01(78.78 \%)$ \\
\hline
\end{tabular}

Values are the mean \pm SEM of eight rats (in duplicate). ${ }^{a}$ Significantly different from the normal control group $(p<0.05){ }^{\text {b }}$ Percent inhibition of serum ALT and hepatic MDA; the percent inhibition is calculated as $100 \times[$ [values of $\mathrm{CCl}_{4}$ control - values of sample)/(values of $\mathrm{CCl}_{4}$ control - values of normal)]; ${ }^{\mathrm{c}}$ Significantly different from the group treated with $\mathrm{CCl}_{4}$ alone $(p<0.05)$.

Taken together, the results of the FTC and DPPH assays suggest that FTE protects against lipid peroxidation by donating hydrogen atoms to terminate the radical chain reaction. The capacity of 
FTE to bind iron may also contribute to its inhibition of peroxidation. The FTE possess the ability to inhibit 5-LOX, as well as free radical scavenging activity. This finding implied that treatment with the FTE caused the inhibition of lipid peroxidation and thus protected against the damaging effects of free radicals induced by the administration of $\mathrm{CCl}_{4}$. Thus, the administration of the FTE resulted in a hepatoprotective effect against the toxic effects of $\mathrm{CCl}_{4}$.

\subsection{Determination of Mushroom Tyrosinase Inhibition In Vitro}

The inhibitory effects of the FTE and a well-known tyrosinase inhibitor, kojic acid (KA), on L-DOPA oxidation by mushroom tyrosinase were concentration-dependent, as shown in Figure 5. The order of potency as determined by the half-inhibition concentration $\left(\mathrm{IC}_{50}, \mu \mathrm{g} / \mathrm{mL}\right)$ was $\mathrm{KA}(2.28 \pm 0.03)>\mathrm{ECG}$ $(76.50 \pm 1.50)>\operatorname{EGC}(110.00 \pm 0.00)>\operatorname{EGCG}(234.00 \pm 6.00)>$ FTE $(349.00 \pm 9.00)$ (Table 2).

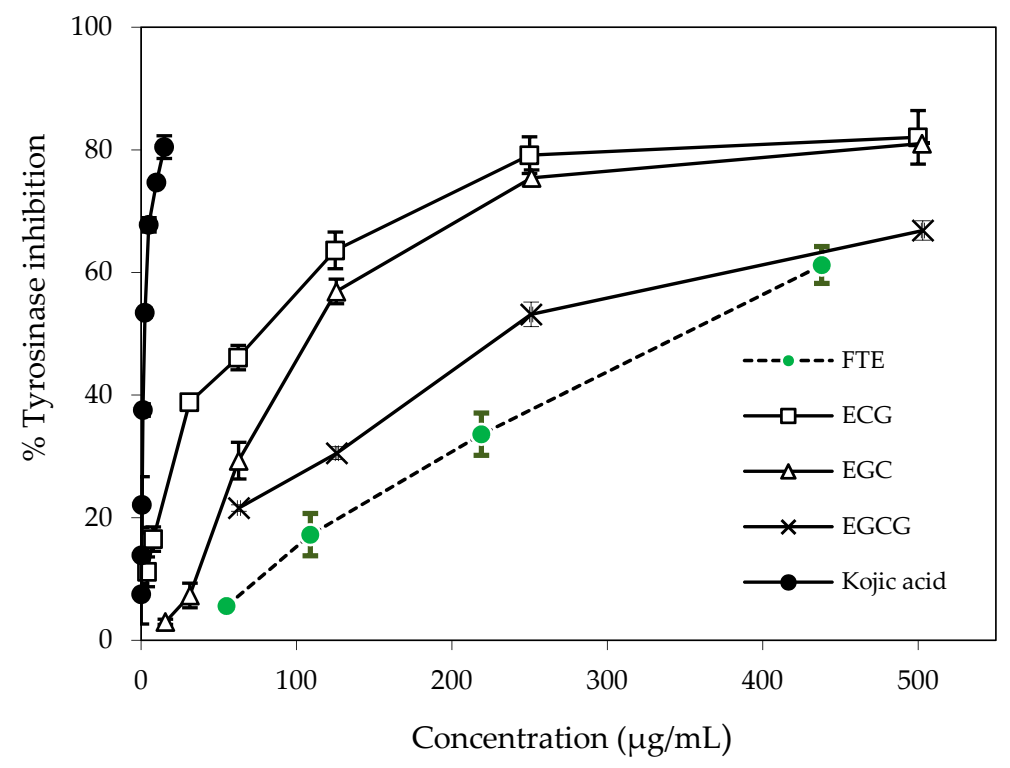

Figure 5. Concentration-dependent inhibition of mushroom tyrosinase by the FTE, its principal phenolic components (ECG, EGC, and EGCG) and kojic acid. Tyrosinase activity was measured using L-DOPA as the substrate. Each value represents the mean $\pm \operatorname{SEM}(n=2)$.

\subsection{Molecular Modelling}

The docking results agreed well with the observed in vitro data, in which the anti-tyrosinase activity of KA was much higher than that of the FTE and its principal phenolic compounds ECG, EGC, and EGCG. Docked KA showed more H-bonding interactions with important amino acids located close to the two copper atoms in the active site of the enzyme compared to ECG, EGC, and EGCG. The selected docked conformations of the structures of KA, ECG, EGC, and EGCG (Figure 6) in the tyrosinase structure are shown in Figure 7, and their GoldScores were 32.40, 57.46, 51.25, and 57.03, respectively. The docked conformation revealed that all ligands were located in the hydrophobic binding pocket surrounding the binuclear copper active site. The locations of docked compounds were consistent with those of docked 2,4-resorcinol derivatives, which can contribute to the potency of the observed tyrosinase inhibitory effect [32]. The docked conformation of KA revealed H-bonding to an oxygen atom of peroxide and the His38, Ile42, His54, Glu182, His190, Asn191, Met201, Thr203, and Ser206 residues in the active site (Figure 8A). Kojic acid also interacted with the His194 ring and showed specific H-bonding to the Phe59 residue. With respect to the docked conformations of ECG, EGC, and EGCG (Figure 8B-D), strong H-bonding was observed with the Ile42 residue. Moreover, an interaction with the His194 ring and common H-bonding to the Asp45, His54, Arg55, Trp184, His190, Asn191, Ala202, and Thr203 residues occurred. For the docked conformation of 
ECG, additional H-bonding interactions were observed with an oxygen atom of peroxide and the His38, His194, Val195, Gly204, and Ser206 residues. The docked conformation of EGC also exhibited H-bonding interactions with the Glu182, His194, Val195, Met201, and Ser206 residues. For the docked conformation of EGCG, H-bonding interactions occurred with an oxygen atom of peroxide and the His194, Met201, Gly204, and Ser206 residues. Compared to EGC and EGCG, ECG formed specific H-bonds with the His38 residue, which was also observed for docked KA. His38, His54, His190, and His194 are important amino acid residues that interact with the two copper ions in the active site. With respect to docked EGC and EGCG, EGC formed specific H-bonds with Glu182, which was also observed in docked KA. Therefore, the docking results agreed well with the results of the in vitro data, which indicated that the anti-tyrosinase potency of the principal catechins of the tea extract was in the order of ECG > EGC > EGCG.

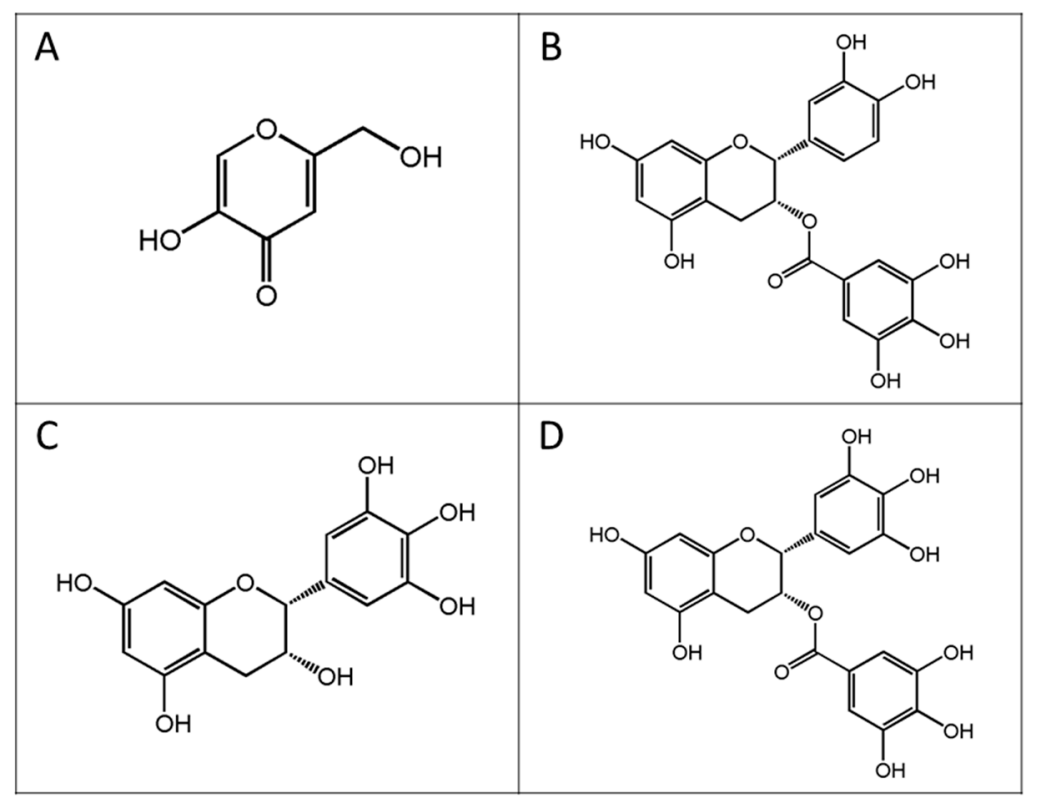

Figure 6. The structures of the compounds used in this study. (A) Kojic acid (KA); (B) Epicatechin-3gallate (ECG); (C) Epigallocatechin (EGC); (D) Epigallocatechin-3-gallate (EGCG).

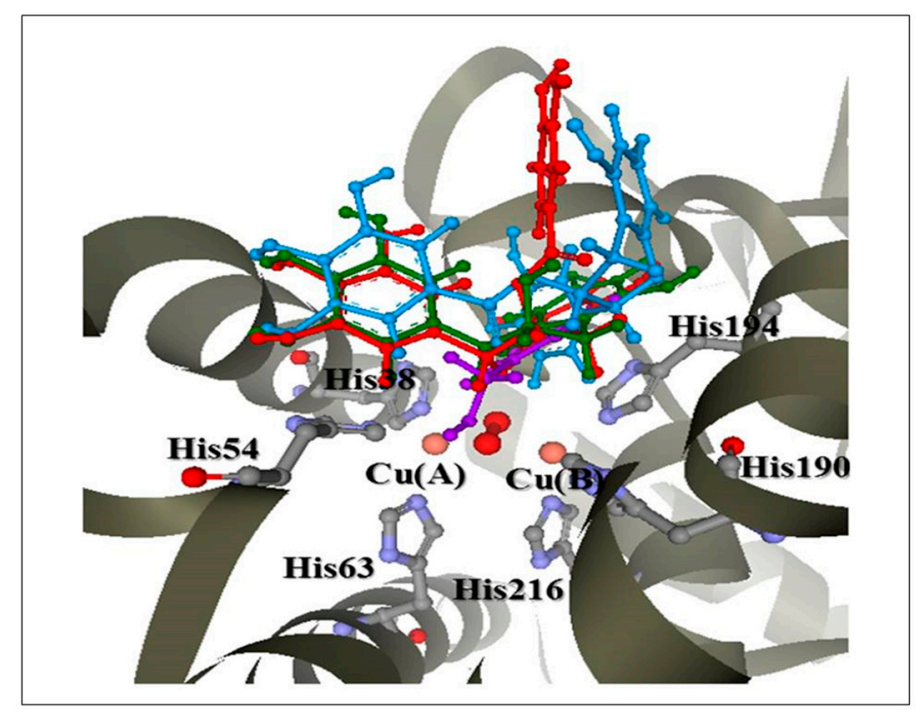

Figure 7. The docked conformations of the ligand structures in the tyrosinase-binding site. KA (Purple), ECG (Blue), EGC (Green), and EGCG (Red). 

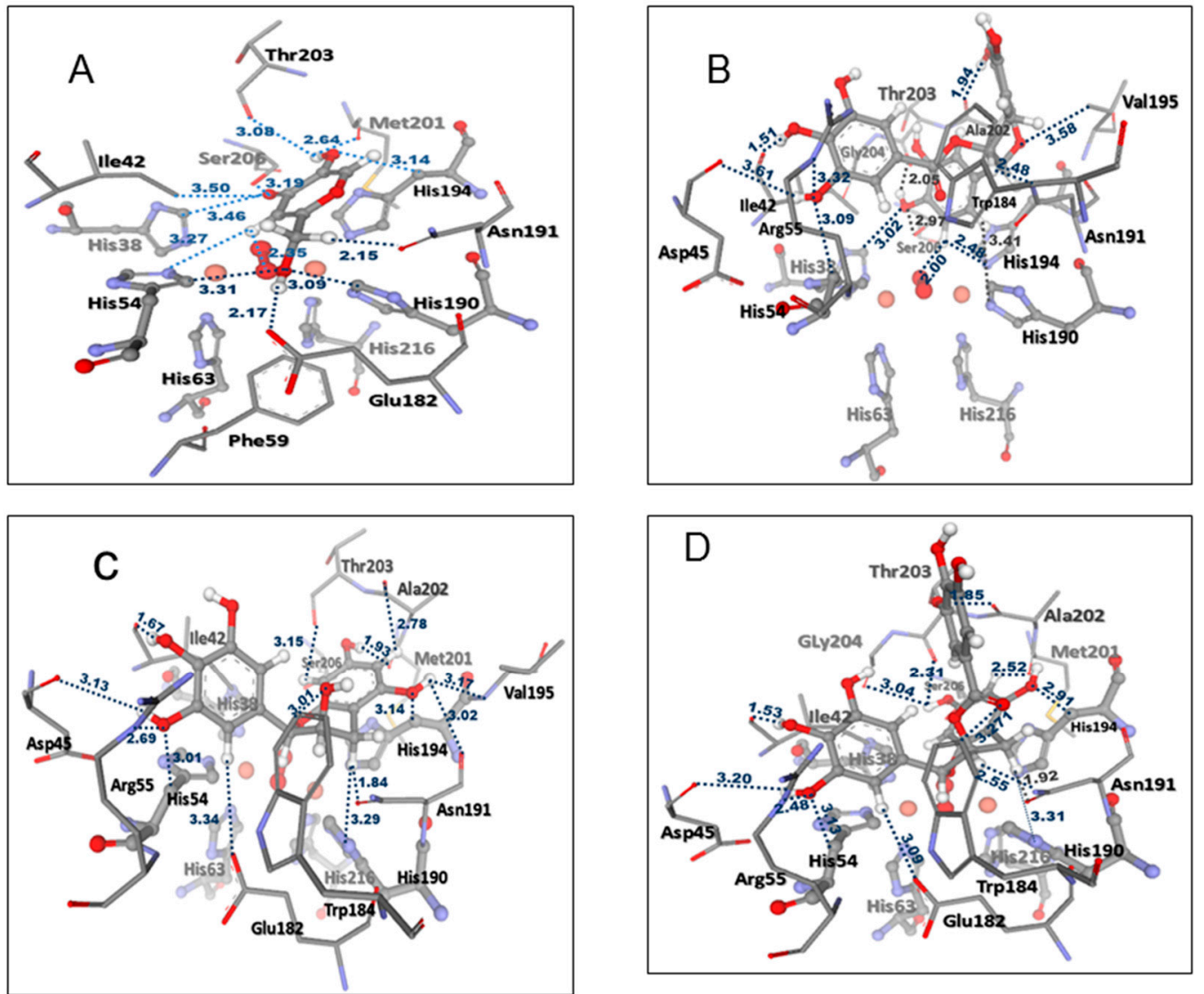

Figure 8. The distances (in $\AA$ ) between the residues in the tyrosinase-binding pocket and ligands: (A) KA; (B) ECG; (C) EGC; and (D) EGCG. Oxygen, nitrogen, carbon, hydrogen, sulfur, and copper atoms are presented in red, violet, grey, white, yellow, and orange color, respectively.

\section{Materials and Methods}

\subsection{Plant Material}

Freshly picked tea leaves (Camellia sinensis L., family Theaceae, cultivar Oolong No. 12) (FTE), including only two leaves and a bud from the terminal branches, were provided by Doi Mae Salong's tea plantation, Chiang Rai, Thailand (5 May 2005). The identities of the samples were confirmed, and a voucher specimen (No. P.B. 20009) was deposited at the Museum of Natural Medicine, Faculty of Pharmaceutical Sciences, Chulalongkorn University, Bangkok, Thailand.

\subsection{Chemicals}

Ascorbic acid (AsA; $\geq 99 \%$ ), 2,2-diphenyl-1-picrylhydrazyl (DPPH; $\geq 85 \%$ ), gallic acid (GA; $\geq 98 \%$ ), kojic acid (KA; $\geq 98 \%$ ), and 2-thiobarbituric acid (TBA; $\geq 98 \%$ ) were purchased from Fluka (Buchs, Switzerland). 5-Lipoxygenase (5-LOX, EC 1.13.11.34, 80,000 units/mg solid), ethylenediaminetetraacetic acid (EDTA; 99.8\%), (-)-epicatechin (EC; $\geq 98 \%)$, (-)-epicatechin3-gallate (ECG; $\geq 98 \%$ ), (-)-epigallocatechin (EGC; $\geq 95 \%$ ), (-)-epigallocatechin-3-gallate (EGCG; $\geq 95 \%$ ), 3-(2-pyridyl)-5,6-bis(4-phenylsulfonic acid)-1,2,4-triazine (ferrozine; $\geq 99 \%$ ), L-3,4-dihydroxyphenylalanine (L-DOPA; $\geq 98 \%$ ), mushroom tyrosinase (EC 1.14.18.1, $\geq 1000$ units/mg solid), nordihydroguaiaretic acid (NDGA; $\geq 97 \%$ ), and silymarin (batch $107 \mathrm{~K} 0762 ; 47 \%$ of silybin) were obtained from Sigma Chemical Co., Ltd. (St. Louis, MO, USA). Butylated hydroxyanisole (BHA; 99.5\%) and butylated hydroxytoluene (BHT; 99.5\%) were obtained from Nikki-Universal Co., 
Ltd. (Tokyo, Japan). DL- $\alpha$-tocopherol was purchased from BASF SE (Ludwigshafen, Germany). All the chemicals and solvents were of analytical grade.

\subsection{Animals}

Male Sprague-Dawley rats weighing 150-200 g were used. They were housed in groups of 2-3 rats/cage with free access to a granular standard diet (C.P. MICE FEED; S.W.T. Co., Ltd., Samut Prakan, Thailand) and drinking water. They were maintained under a $12 \mathrm{~h}$ light-dark cycle at a temperature of $23 \pm 2{ }^{\circ} \mathrm{C}$ and a humidity of approximately $65 \%-70 \%$ for at least 1 week before use. The basic parameters related to the animals such as body weight, food intake, etc. were not monitored during the experiment but were only evaluated at the beginning of the experiment.

The experimental protocol (No. 0014) was approved by the Institutional Animal Care and Use Committee of the Faculty of Pharmacy, Mahidol University, in accordance with the Ethical Principles and Guidelines for the Use of Animals for Scientific Purposes by the National Research Council of Thailand, Ministry of Science and Technology.

\subsection{Preparation and Standardization of Plant Extract}

The leaves $(10.66 \mathrm{~kg})$ were thoroughly washed, chopped, and macerated using methanol $(70 \%)$ as the extracting solvent at a ratio of fresh tea leaves/solvent $=1: 2(w / v)$ for $24 \mathrm{~h}$ at room temperature $\left(30{ }^{\circ} \mathrm{C}\right)$. Subsequently, the methanolic extract was filtered and the residue was remacerated 4 times with fresh methanol (70\%). The combined methanolic solution was centrifuged at $2000 \mathrm{rpm}$ for $15 \mathrm{~min}$ in a Hettich Roto Magna ${ }^{\circledR}$ and concentrated in a rotary evaporator (model SB-650, Tokyo Rikakikai Co. Ltd., Japan) at $35{ }^{\circ} \mathrm{C}$. The extract was decaffeinated with dichloromethane, evaporated under reduced pressure, and then freeze dried to produce a crude, fresh tea leaf extract with a yield of $9.40 \%$ $(w / w)$. The total phenolic content of the extract was analysed using the Folin-Ciocalteu colorimetric method [33]. The FTE was found to contain $245.20 \pm 4.92 \mathrm{mg} / \mathrm{g}$ of total phenolic compounds expressed as the gallic acid equivalent (GAE, $\mathrm{mg} / \mathrm{g}$ of extract).

The dried extract was analysed for the contents of four catechins-EC, ECG, EGC, and EGCG—using a reverse-phase high-performance liquid chromatography (HPLC) method [34]. The HPLC analysis was performed using a Shimadzu model LC-10AD (Tokyo, Japan), consisting of a binary pump, SIL-10ADVP autosampler, and an SPD-10AVP detector (UV-Vis absorbance detector) and equipped with an Alltech Altima ${ }^{\circledR} \mathrm{C} 18$ column $(4.6 \times 150 \mathrm{~mm}, 5 \mu \mathrm{m})$. An isocratic mode was used, and the mobile phase was $0.1 \%$ phosphoric acid in water/acetonitrile $(85: 15, v / v)$. The flow rate was $1 \mathrm{~mL} / \mathrm{min}$, and the injection volume was $10 \mu \mathrm{L}$. Detection was conducted at $280 \mathrm{~nm}$, and the identification of individual catechins was based on the comparison of the retention time and UV spectrum of unknown peaks with those of authentic reference standards. Four individual catechins were quantified in the FTE by comparison with the generated standard curves (peak area vs. concentration). The methanolic extract of the freshly picked tea leaves was found to contain 11.7, 16.1, 72.1, and $89.7 \mathrm{mg} / \mathrm{g}$ dry weights of ECG, EC, EGCG, and EGC, respectively.

\subsection{Antioxidant Activity Assay}

\subsubsection{Determination of Lipid Peroxidation Inhibition Using the FTC Method}

The FTC method [35] was used to determine the in vitro inhibition of linoleic acid peroxidation. In this study, $0.1 \mathrm{~mL}$ of each sample was added to the assay mixture. Antioxidant activity was calculated as the percent inhibition of linoleic acid peroxidation versus control. BHA, BHT, tocopherol, and AsA were used as positive references. The effects of temperature variation and storage period on the inhibition of lipid peroxidation were investigated by incubating the samples at $8{ }^{\circ} \mathrm{C}, 30^{\circ} \mathrm{C}$, and $40^{\circ} \mathrm{C}$ during a period of up to 120 days. 


\subsubsection{Determination of Radical Scavenging Activity Using the DPPH Test}

The DPPH method [36] was used to determine the free radical-scavenging potential of each sample. The test sample $(0.1 \mathrm{~mL})$ was added to $3.9 \mathrm{~mL}$ of DPPH solution $\left(6 \times 10^{-5} \mathrm{M}\right)$. The absorbance was measured at $515 \mathrm{~nm}$ after $30 \mathrm{~min}$ of the reaction at room temperature $\left(30^{\circ} \mathrm{C}\right)$. The antiradical activity was calculated as a percentage of DPPH decolouration versus a control. The results were expressed as the concentration of the FTE that scavenged $50 \%$ of the free radicals from the reaction mixture $\left(\mathrm{SC}_{50}\right)$. The percent $\mathrm{DPPH}$ scavenging effect was calculated by using following equation [37]:

$$
\text { DPPHscavengingeffect }(\%) \text { orPercentinhibition }=\left[\frac{\mathrm{Ao}-\mathrm{At}}{\mathrm{Ao}}\right] \times 100
$$

where $A_{o}$ is the absorbance of the control reaction and $A_{t}$ is the absorbance in the presence of a test or standard sample. AsA, BHA, BHT, and tocopherol were used as positive references.

\subsubsection{Chelation of Ferrous Metal Ions}

The method of Gülçin et al. [38] was followed. The reaction mixture, containing different concentrations of each sample, $\mathrm{FeCl}_{2}(2 \mathrm{mM})$, and ferrozine $(1.5 \mathrm{mM})$, was adjusted to a total volume of $4 \mathrm{~mL}$ with absolute methanol, shaken well, and incubated for $10 \mathrm{~min}$ at room temperature $\left(30^{\circ} \mathrm{C}\right)$. The absorbance of the mixture was measured at $562 \mathrm{~nm}$ against a blank. EDTA was used as the positive reference. The percent inhibition of ferrozine- $\mathrm{Fe}^{2+}$ complex formation was calculated against a control. The results were expressed as the concentration of the FTE that chelated $50 \%$ of metal ions $\left(\mathrm{IC}_{50}\right)$.

\subsection{Determination of In Vitro Anti-Inflammatory Activity by the Inhibition of 5-LOX}

The method of Baylac and Racine [39] was followed. The assay mixture (3 mL) consisted of $2 \mathrm{mM}$ linoleic acid, $50 \mu \mathrm{L}$ of each sample at various concentrations in distilled water, and $750 \mu \mathrm{L}$ of freshly prepared 5-LOX (3200 units $/ \mathrm{mL}$ ) in $0.2 \mathrm{M}$ borate buffer $(\mathrm{pH} 9)$. The reaction was initiated by the addition of linoleic acid. The increase in absorption at $234 \mathrm{~nm}$ was monitored for $5 \mathrm{~min}$ at $25^{\circ} \mathrm{C}$. The initial reaction rate was determined from the slope of the straight-line portion of the curve, and the percentage inhibition of enzyme activity was calculated by comparison with the positive control, NDGA. The extent of inhibition of the test samples was expressed as the percentage of concentration necessary to achieve $50 \%$ inhibition $\left(\mathrm{IC}_{50}\right)$.

\subsection{Determination of the Anti-Hepatotoxic Effects of the FTE on $\mathrm{CCl}_{4}$-Induced Liver Injury in Rats}

Animals were divided into six groups consisting of eight animals in each group. Group 1 served as the normal control and received distilled water $(1 \mathrm{~mL} / \mathrm{kg}$ body weight per day). Group 2 served as the $\mathrm{CCl}_{4}$-treated control and received distilled water $(1 \mathrm{~mL} / \mathrm{kg}$ body weight per day). Groups 3-5 (extract treatment) were treated with the FTE at doses of 500, 1000, and $2000 \mathrm{mg} / \mathrm{kg}$ body weight per day, respectively. Group 6 (extract alone) was treated with the FTE at a dose of $2000 \mathrm{mg} / \mathrm{kg}$ body weight per day. Silymarin was selected as an internal positive control in this study and therefore, group 7 served as the silymarin-positive control-treated group and received a dose of $100 \mathrm{mg} / \mathrm{kg}$ body weight per day. All treatments were administered orally for 28 days. With the exception of groups 1 and 6, all other groups received $\mathrm{CCl}_{4}$ :liquid paraffin $(1: 2,1 \mathrm{~mL} / \mathrm{kg}$ body weight, i.p.) on days 23,26 , and 29 . The rationale to select the doses of $\mathrm{CCl}_{4}$ was based on the literature study with modification [40-43]. On day 30, the rats were anesthetized using diethyl ether; blood samples were collected from the abdominal artery, and the liver was removed. The serum was separated from the blood, and the serum and the liver samples were stored at $-80^{\circ} \mathrm{C}$ until analysis.

\subsubsection{ALT Assay}

The activity of ALT was determined from the obtained serum and evaluated using an ALT assay kit (Audit, Ireland). One hundred microliters of the sample serum were added to $1 \mathrm{~mL}$ of test reagent 
in a $1 \mathrm{~cm}$ light path cuvette. After incubation at $37^{\circ} \mathrm{C}$ for $1 \mathrm{~min}$, measurements were taken of the changes in optical density per minute $(\Delta \mathrm{OD} / \mathrm{min})$ during the next $3 \mathrm{~min}$ at a wavelength of $340 \mathrm{~nm}$. Enzyme activity was expressed as $\mathrm{U} / \mathrm{L}$ and calculated as follows:

$$
\text { Enzymeactivity }(\mathrm{U} / \mathrm{L})=\Delta \mathrm{OD} / \mathrm{min} \times 1746
$$

\subsubsection{Thiobarbituric Acid (TBA) Assay}

The method of Ohkawa et al. [44] was followed for this experiment. The mixture was prepared by combining $0.1 \mathrm{~mL}$ of liver homogenate with $0.2 \mathrm{~mL}$ of $8.1 \%$ sodium lauryl sulphate (SLS), $1.5 \mathrm{~mL}$ of $20 \%$ acetic acid solution at $\mathrm{pH} 3.5$, and $1.5 \mathrm{~mL}$ of $0.8 \%$ aqueous solution of TBA. The mixture was brought up to $4 \mathrm{~mL}$ with distilled water and heated at $95^{\circ} \mathrm{C}$ for $60 \mathrm{~min}$ in a water bath. After cooling, $1 \mathrm{~mL}$ of distilled water and $5 \mathrm{~mL}$ of a mixture of $n$-butanol and pyridine $(15: 1, v / v)$ were added, and the mixture was shaken vigorously. After centrifugation at $4000 \mathrm{rpm}$ for $10 \mathrm{~min}$, the absorbance of the organic layer (upper layer) was measured at $532 \mathrm{~nm}$. 1,1,3,3-Tetramethoxypropane (TMP) was used as an external standard. The lipid peroxide level was expressed as nmol of MDA.

\subsection{Determination of Mushroom Tyrosinase Inhibition In Vitro}

The dopachrome method [45] was used to determine the anti-tyrosinase activity of the FTE and its principal catechins (ECG, EGC, and EGCG) compared with that of the standard tyrosinase-inhibitor control, KA. Briefly, $120 \mu \mathrm{L}$ of $20 \mathrm{mM}$ phosphate buffer ( $\mathrm{pH}$ 6.8), $40 \mu \mathrm{L}$ of 48 units/mL mushroom tyrosinase, and $20 \mu \mathrm{L}$ of various sample concentrations with or without enzyme were placed in the wells of a 96-well microplate. After pre-incubation at $25^{\circ} \mathrm{C}$ for $10 \mathrm{~min}, 20 \mu \mathrm{L}$ of $0.85 \mathrm{mM}$ L-DOPA was added, and the plate was subsequently incubated at $25^{\circ} \mathrm{C}$ for $20 \mathrm{~min}$. The amount of dopachrome was measured at $492 \mathrm{~nm}$ in an ELISA plate reader (Anthos 2010, Anthos Labtec Instruments GmbH, Wals, Austria). The extent of inhibition by the test samples was expressed as the percentage of concentration necessary to achieve $50 \%$ inhibition $\left(\mathrm{IC}_{50}\right)$.

\subsection{Molecular Modelling}

Docking studies of ECG, EGC, EGCG and the positive reference (KA) were carried out. The structures of these compounds (Figure 6) were constructed and optimized at the HF/3-21G level of theory using a Gaussian 03 program [46]. For the preparation of the tyrosinase structure, the crystal structure of the oxy form of tyrosinase was taken from the Protein Data Bank (PDB code 1wx2) [25]. Caddie protein (ORF378) and water molecules were removed. Hydrogen atoms were added to the enzyme using the SYBYL version 7.2 program (TRIPOS, Association Inc., St. Louis, MO, USA). The molecular docking method was conducted using the Gold version 3.2 program [27] to study the binding orientation of ECG, EGC, EGCG, and KA in the tyrosinase structure. The radius of the binding site was set to $10 \AA$. The default parameters of the automatic settings were used for setting the genetic algorithm parameters. The docked conformation with the highest GoldScore was selected to analyse the mode of binding.

\subsection{Statistical Analysis}

The data were presented as the mean \pm SD or mean \pm SEM. All statistical analyses were carried out using SPSS 13.0 for Windows. Significant differences $(p<0.05)$ between the means were assessed using one-way ANOVA, followed by Scheffé's method or Dunnett's T3 test for multiple comparisons.

\section{Conclusions}

In conclusion, the FTE demonstrates potential beneficial antioxidant, anti-inflammatory, and anti-hepatotoxic activities both in vitro and in vivo. The FTE is most effective at low temperatures and degrades rapidly at high temperatures. The docking results provide an explanation for the abilities of 
the catechin compounds to inhibit tyrosinase. This information may be helpful to use as a guideline for designing potent tyrosinase inhibitors.

Acknowledgments: This research was partially supported by Wiang Haeng Hospital, Chiang Mai, Thailand. We would like to acknowledge Wichai Cheewinkulthong, Managing Director of Wang Put Tan Co. Ltd., 7/1 Moo 12, Mae Salong Nok, Mae Fahluang, Chiang Rai, Thailand, for providing the fresh tea leaves for this study.

Author Contributions: Surached Thitimuta conceived and performed the experiments; Patchreenart Saparpakorn designed, performed, and analyzed the molecular modelling experiment. Jiraporn Leanpolchaleanchai analyzed the data and rechecked the manuscript; Rapepol Bavovada contributed to the plant extraction and identification of the phenolic principles; Saruth Nithitanakool performed one part of the anti-tyrosinase experiment and prepared some parts of the draft manuscript; Pimolpan Pithayanukul, the project advisor, designed the experiments, analyzed the data, and wrote the paper.

Conflicts of Interest: The authors declare no conflict of interest.

\section{References}

1. Poli, G. Liver damage due to free radicals. Br. Med. Bull. 1993, 49, 604-620. [CrossRef] [PubMed]

2. Vrba, J.; Modriansky, M. Oxidative burst of Kupffer cells: Target for liver injury treatment. Biomed. Pap. Med. Fac. Univ. Palacky Olomouc Czech Repub. 2002, 146, 15-20. [CrossRef] [PubMed]

3. Handa, S.S.; Sharma, A.; Chakraborti, K.K. Natural products and plants as liver protecting drugs. Fitoterapia 1986, 57, 307-352.

4. Henning, S.M.; Niu, Y.; Liu, Y.; Lee, N.H.; Hara, Y.; Thames, G.D.; Minutti, R.R.; Carpenter, C.L.; Wang, H.; Heber, D. Bioavailability and antioxidant effect of epigallocatechin gallate administered in purified form versus as green tea extract in healthy individuals. J. Nutr. Biochem. 2005, 16, 610-616. [CrossRef] [PubMed]

5. Camargo, L.E.; Pedroso, L.S.; Vendrame, S.C.; Mainardes, R.M.; Khalil, N.M. Antioxidant and antifungal activities of Camellia sinensis (L.) Kuntze leaves obtained by different forms of production. Braz. Biol. 2016, 76, 428-434. [CrossRef] [PubMed]

6. Gramza-Michałowska, A.; Kobus-Cisowska, J.; Kmiecik, D.; Korczak, J.; Helak, B.; Dziedzic, K.; Górecka, D. Antioxidative potential, nutritional value and sensory profiles of confectionery fortified with green and yellow tea leaves (Camellia sinensis). Food Chem. 2016, 211, 448-454. [CrossRef] [PubMed]

7. Obanda, M.; Owuor, P.O.; Taylor, S.J. Flavanol composition and caffeine content of green leaf as quality potential indicators of Kenyan black teas. J. Sci. Food Agric. 1997, 74, 209-215. [CrossRef]

8. Katiyar, S.K.; Agarwal, R.; Zaim, M.T.; Mukhtar, H. Protection against N-nitrosodiethylamine and benzo[a]pyrene-induced forestomach and lung tumorigenesis in A/J mice by green tea. Carcinogenesis 1993, 14, 849-855. [CrossRef] [PubMed]

9. Yoshino, K.; Hara, Y.; Sano, M.; Tomita, I. Antioxidative effects of black tea theaflavins and thearubigin on lipid peroxidation of rat liver homogenates induced by tert-butyl hydroperoxide. Biol. Pharm. Bull. 1994, 17, 146-149. [CrossRef] [PubMed]

10. Yen, G.C.; Chen, H.Y. Antioxidant activity of various tea extracts in relation to their antimutagenicity. J. Agric. Food Chem. 1995, 43, 27-32. [CrossRef]

11. Tipoe, G.L.; Leung, T.M.; Hung, M.W.; Fung, M.L. Green tea polyphenols as an anti-oxidant and anti-inflammatory agent for cardiovascular protection. Cardiovasc. Hematol. Disord. Drug Targets 2007, 7, 135-144. [CrossRef] [PubMed]

12. Kim, Y.C.; Choi, S.Y.; Park, E.Y. Anti-melanogenic effects of black, green, and white tea extracts on immortalized melanocytes. J. Vet. Sci. 2015, 16, 135-143. [CrossRef] [PubMed]

13. He, P.; Noda, Y.; Sugiyama, K. Green tea suppresses lipopolysaccharide-induced liver injury in D-galactosamine-sensitized rats. J. Nutr. 2001, 131, 1560-1567. [PubMed]

14. Ostrowska, J.; Łuczaj, W.; Kasacka, I.; Rózański, A.; Skrzydlewska, E. Green tea protects against ethanol-induced lipid peroxidation in rat organs. Alcohol 2004, 32, 25-32. [CrossRef] [PubMed]

15. El-Beshbishy, H.A. Hepatoprotective effect of green tea (Camelliasinensis) extract against tamoxifen-induced liver injury in rats. J. Biochem. Mol. Biol. 2005, 38, 563-570. [PubMed]

16. Issabeagloo, E.; Taghizadieh, M. Hepatomodulatory action of Camellia sinensis aqueous extract against isoniazid-rifampicin combination induced oxidative stress in rat. Adv. Biomed. Res. 2012, 3, 18-27. 
17. Lodhi, P.; Tandan, N.; Singh, N.; Kumar, D.; Kumar, M. Camellia sinensis (L.) Kuntze extract ameliorates chronic ethanol-induced hepatotoxicity in albino rats. Evid.-Based Complement. Altern. Med. 2014, 2014, 787153. [CrossRef] [PubMed]

18. Nerya, O.; Ben-Arie, R.; Luzzatto, T.; Musa, R.; Khatib, S.; Vaya, J. Prevention of Agaricus bisporus postharvest browning with tyrosinase inhibitors. Postharvest Biol. Technol. 2006, 39, 272-277. [CrossRef]

19. Hearing, V.J.; Jimenez, M. Analysis of mammalian pigmentation at the molecular level. Pigment Cell Res. 1989, 2, 75-85. [CrossRef] [PubMed]

20. Seo, S.Y.; Sharma, V.K.; Sharma, N. Mushroom tyrosinase: Recent prospects. J. Agric. Food Chem. 2003, 51, 2837-2853. [CrossRef] [PubMed]

21. Kim, Y.J.; Uyama, H. Tyrosinase inhibitors from natural and synthetic sources: Structure, inhibition mechanism and perspective for the future. Cell. Mol. Life Sci. 2005, 62, 1707-1723. [CrossRef] [PubMed]

22. Maeda, K.; Fukuda, M. Arbutin: Mechanism of its depigmenting action in human melanocytes. J. Pharmacol. Exp. Ther. 1996, 276, 765-769. [PubMed]

23. Shimogaki, H.; Tanaka, Y.; Tamai, H.; Masuda, M. In vitro and in vivo evaluation of ellagic acid on melanogenesis inhibition. Int. J. Cosmet. Sci. 2000, 22, 291-303. [CrossRef] [PubMed]

24. Cabanes, J.; Chazarra, S.; Garcia-Carmona, F. Kojic acid, a cosmetic skin whitening agent, is a slow-binding inhibitor of catecholase activity of tyrosinase. J. Pharm. Pharmacol. 1994, 46, 982-985. [CrossRef] [PubMed]

25. Matoba, Y.; Kumagai, T.; Yamamoto, A.; Yoshitsu, H.; Sugiyama, M. Crystallographic evidence that the dinuclear coppercenter of tyrosinase is flexible during catalysis. J. Biol. Chem. 2006, 281, 8981-8990. [CrossRef] [PubMed]

26. Nithitanakool, S.; Pithayanukul, P.; Bavovada, R.; Saparpakorn, P. Molecular docking studies and anti-tyrosinase activity of Thai mango seed kernel extract. Molecules 2009, 14, 257-265. [CrossRef] [PubMed]

27. Jones, G.; Willett, P.; Glen, R.C.; Leach, A.R.; Taylor, R. Development and validation of a genetic algorithm for flexible docking. J. Mol. Biol. 1997, 267, 727-748. [CrossRef] [PubMed]

28. Pokorný, J. Addition of antioxidants for food stabilization to control oxidative rancidity. Czech J. Food Sci. 1986, 4, 299-307.

29. Farhoosh, R.; Golmovahhed, G.A.; Khodaparast, M.H.H. Antioxidant activity of various extracts of old tea leaves and black tea wastes (Camellia sinensis L.). Food Chem. 2007, 100, 231-236. [CrossRef]

30. Young, R.N. Inhibitors of 5-lipoxygenase: A therapeutic potential yet to be fully realized? Eur. J. Med. Chem. 1999, 34, 671-685. [CrossRef]

31. Frum, Y.; Viljoen, A.M. In vitro 5-lipoxygenase and anti-oxidant activities of South African medicinal plants commonly used topically for skin diseases. Skin Pharmacol. Physiol. 2006, 19, 329-335. [CrossRef] [PubMed]

32. Khatib, S.; Nerya, O.; Musa, R.; Tamir, S.; Peter, T.; Vaya, J. Enhanced substituted resorcinol hydrophobicity augments tyrosinase inhibition potency. J. Med. Chem. 2007, 50, 2676-2681. [CrossRef] [PubMed]

33. Singleton, V.L.; Orthofer, R.; Lamuela-Raventós, R.M. Analysis of total phenols and other oxidation substrates and antioxidants by means of Folin-Ciocalteu reagent. Methods Enzymol. 1999, 299, 152-178.

34. Wang, H.; Helliwell, K.; You, X. Isocratic elution system for the determination of catechins, caffeine and gallic acid in green tea using HPLC. Food Chem. 2000, 68, 115-121.

35. Kikuzaki, H.; Nakatani, N. Antioxidant effects of some ginger constituents. J. Food Sci. 1993, 58, 1407-1410. [CrossRef]

36. Brand-Williams, W.; Cuvelier, M.E.; Berset, C. Use of a free radical method to evaluate antioxidant activity. LWT Food Sci. Technol. 1995, 28, 25-30. [CrossRef]

37. Tailor, C.S.; Goyal, A. Antioxidant activity by DPPH radical scavenging method of Ageratum conyzoides Linn. leaves. Am. J. Ethnomed. 2014, 1, 244-249.

38. Gülçin, I.; Elmastaş, M.; Aboul-Enein, H.Y. Determination of antioxidant and radical scavenging activity of Basil (Ocimum basilicum L. Family Lamiaceae) assayed by different methodologies. Phytother. Res. 2007, 21, 354-361. [CrossRef] [PubMed]

39. Baylac, S.; Racine, P. Inhibition of 5-lipoxygenase by essential oils and other natural fragrant extracts. Int. J. Aromather. 2003, 13, 138-142. [CrossRef]

40. Mishra, S.; Sahoo, S.; Rout, K.K.; Nayak, S.K.; Mishra, S.K.; Panda, P.K. Hepatoprotective effect of Barringtonia acutangula Linn. leaves on carbon tetrachloride-induced acute liver damage in rats. Indian J. Nat. Prod. Resour. 2011, 2, 515-519. 
41. Pandit, S.; Sur, T.K.; Jana, U.; Debnath, P.K.; Sen, S.; Bhattacharyya, D. Prevention of carbon tetrachloride-induced hepatotoxicity in rats by Adhatoda vasica leaves. Indian J. Pharmacol. 2004, 36, 312-320.

42. Mahli, A.; Koch, A.; Czech, B.; Peterburs, P.; Lechner, A.; Haunschild, J.; Müller, M.; Hellerbrand, C. Hepatoprotective effect of oral application of a silymarin extract in carbon tetrachloride-induced hepatotoxicity in rats. Clin. Phytosciol. 2015. [CrossRef]

43. Bezenjani, S.N.; Pouraboli, I.; Afshar, R.M.; Mohammadi, G. Hepatoprotective effect of Otostegia persica Boiss. shoot extract on carbon tetrachloride-induced acute liver damage in rats. Iran. J. Pharm. Res. 2012, 11, 1235-1241.

44. Ohkawa, H.; Ohishi, N.; Yagi, K. Assay for lipid peroxides in animal tissues by thiobarbituric acid reaction. Anal. Biochem. 1979, 95, 351-358. [CrossRef]

45. Iida, K.; Hase, K.; Shimomura, K.; Sudo, S.; Kadota, S.; Namba, T. Potent inhibitors of tyrosinase activity and melanin biosynthesis from Rheum officinale. Planta Med. 1995, 61, 425-428. [CrossRef] [PubMed]

46. Frisch, M.J.; Trucks, G.W.; Schlegel, H.B.; Scuseria, G.E.; Robb, M.A.; Cheeseman, J.R.; Montgomery, J.A., Jr.; Vreven, T.; Kudin, K.N.; Burant, J.C.; et al. Gaussian 03; Gaussian, Inc.: Pittsburgh, PA, USA, 2003.

Sample Availability: Samples of the compounds are available from the authors.

(c) 2017 by the authors. Licensee MDPI, Basel, Switzerland. This article is an open access article distributed under the terms and conditions of the Creative Commons Attribution (CC BY) license (http:/ / creativecommons.org/licenses/by/4.0/). 